Western University

Scholarship@Western

Department of Economics Research Reports

Economics Working Papers Archive

1970

\title{
The Theory of Wage Differentials: Welfare and Immiserizing Growth
}

Raveendra Batra

Gerald W. Scully

Follow this and additional works at: https://ir.lib.uwo.ca/economicsresrpt

Part of the Economics Commons

Citation of this paper:

Batra, Raveendra, Gerald W. Scully. "The Theory of Wage Differentials: Welfare and Immiserizing Growth." Department of Economics Research Reports, 7028. London, ON: Department of Economics, University of Western Ontario (1970). 
RESEARCH REPORT 7028

THE THEORY OF WAGE DIFFERENTIALS :

WELFARE AND IMMISERIZING GROWTH

by

Raveendra Batra*

and

Gerald W. Scully

*The authors are respectively Assistant Professors of Economics at the University of Western Ontario and Southern Illinois University. 
THE THEORY OF WAGE DIFFERENTIALS:

WELFARE AND TMMISERIZING GRONTH*

In this paper, we propose to argue the following three propositions in the theory of trade and welfare when a distortionary wage differential is present:

i) if there is an exogenous improvement in the terms of trade, this may worsen rather than improve welfare;

ii) if the country is large (i.e., there is monopoly power in trade), an endogenous, own-growth-induced improvement in the terms of trade may reduce rather than increase the rate of growth; and

iii) if the country is large, an endogenous, own-growth-induced improvement in the terms of trade may be compatible with immiserizing growth.

These propositions are established in the first three sections of the paper. In the fourth section we provide underlying rationale for these propositions by drawing on Bhagwati's recent work on the theory of immiserizing growth.

We deploy throughout the analysis the traditional, standard model of trade theory, where given supplies of two primary factors produce two traded commodities, modifying it only to introduce a wage differential between the two sectors. We also rule out, for convenience, the possibility that when a wage differential is present, there may be perverse response of output to price-change: a possibility established recently by Bhagwati-Srinivasan (1970) and Kemp-Herberg (1969). In our geometrical illustration., furthermore, we abstract from the possibility that the wage differential may cause the feasible production possibility curve to become 
convex to the origin (Fishlow and David, 1961; Bhagwati and Ramaswami, 1963; and Johnson, 1966). Note finally that the analysis of this paper applies equally to the case where there is a production externality resulting in a divergence between private and social opportunity costs.

\section{I}

The proposition that an exogenous improvement in the terms of trade may worsen welfare in the presence of a wage differential has been stated earlier by Batra and Pattanaik (1970). We establish this proposition here more formally and elaborate it further.

Assuming commodities $x_{1}$ and $x_{2}$ to be produced with the following linear, homogeneous production functions:

$$
x_{1}=F_{1}\left(K_{1}, L_{1}\right)
$$

and

$$
\mathrm{X}_{2}=\mathrm{F}_{2}\left(\mathrm{~K}_{2}, \mathrm{~L}_{2}\right) \text {; }
$$

and assuming that the rate of return on capital is the same in both industries, but that there is a stable wage differential between the industries (such that $\mathrm{cw}_{1}=w_{2}$ ), we get the standard result for a competitive economy with given supplies of the two factors, $K$ and $L$, that:

$$
\frac{\mathrm{dx}_{2}}{\mathrm{dx}_{1}}=\frac{\mu_{2} \mathrm{dL}_{2}+\mathrm{v}_{2} \mathrm{dK}_{2}}{\mu_{1} \mathrm{dL}_{1}+\mathrm{v}_{1} \mathrm{dK}_{1}}
$$

$$
\text { where } \quad \begin{aligned}
\mu_{i} & =\frac{\partial F_{i}}{\partial L_{i}} \\
v_{i} & =\frac{\partial F_{i}}{\partial K_{i}}
\end{aligned} \quad i=1,2
$$

Hence, the commodity price-ratio $p=p_{1} / p_{2}$, (which is the same as the 
international terms of trade, given the assumption of free trade throughout our analysis), is seen to be:

$$
\frac{d x_{2}}{d x_{1}}=-\beta p
$$

where $\beta=\left(v_{1} d K_{1}+\alpha \mu_{1} d L_{1}\right) /\left(v_{1} d K_{1}+\mu_{1} d L_{1}\right) .^{1}$

It is easy to see that:

$$
\beta \gtreqless 1 \text { according as } \alpha \gtreqless 1 \text {. }
$$

Now, define national income, $Y$, in $x_{2}$-units as follows:

$$
\mathrm{Y}=\mathrm{pX}_{1}+\mathrm{X}_{2}
$$

We can then derive:

$$
\frac{d Y}{d p}=X_{1}\left[1+\eta_{1}(1-\beta)\right]
$$

where $\eta_{1}=\frac{\mathrm{p}}{\mathrm{X}_{1}} \cdot \frac{\mathrm{dX}}{\mathrm{dp}}$ is the (total) elasticity of the production of conmodity $x_{1}$ with respect to the terms of trade.

Let us now distinguish three cases:

1) If $\beta=1$, (i.e., there is no wage differential), then

$$
\frac{d Y}{d p}=x_{1}>0 \text {. }
$$

We therefore derive the standard result that an improvement (deterioration) in the terms of trade, in the absence of an inter-industry wage differential, results in an increase (decrease) in national income.

2) If $\beta<1$, with $\eta$ positive, the improvement (deterioration) in the terms of trade still yields an increase (decrease) in national income. In fact the rise (fal1) in national income is even greater than in the case where no inter-industry wage differential existed at all. Note further that if $\beta<1$, then $\alpha<1$, implying that $w_{1}>w_{2}$. Hence if the wage differential works against $x_{1}$, the exportable commodity, and if the pattern of trade is not 
reversed, the conventional result, that an improvement (deterioration) in the terms of trade results in an increase (decrease) in welfare, continues to hold.

3) If $\beta>1$ (i.e., if $\alpha>1$ or $w_{1}<w_{2}$, that is, if the wage differential works against $x_{2}$, the importable commodity), it is possible that $\mathrm{dY} / \mathrm{dp}<0$. This will occur if

$$
1+\frac{1}{\eta_{1}}<\beta \text {. }
$$

In other words, if $\beta$ is greater than unity plus the inverse of the (total) elasticity of export production with respect to price-change, then an improvement in the terms of trade will lead to a decline in national income. Symmetrically, a deterioration in the terms of trade will lead to a rise in national income. Therefore, the unique relationship between the terms of trade and national income breaks down in the presence of an inter-industry wage differential, provided $\beta>1$.

\section{II}

We now extend this analysis to our Proposition (ii), which relates to the effect of the wage differential, in contrast to the absence thereof, on the rate of growth of national income of the country.

To examine this issue, we differentiate the income equation totally to get:

$$
d Y=\left.\partial Y\right|_{\vec{p}}+\left.\frac{\partial Y}{\partial p}\right|_{\bar{G}} \cdot d p
$$

where the total change in income is the sum of two partial changes: change in income, at constant prices, as growth occurs; and change in income due to price-change, holding income growth constant. ${ }^{2}$ on substituting (3) into (4), we get: 


$$
\frac{d Y}{Y}=\frac{\left.\partial Y\right|_{\bar{P}}}{Y}+\frac{d P}{Y}\left[X_{1}\left\{1+\eta_{1}(1-\beta)\right\}\right]
$$

We can then distinguish three cases:

1) If there is no inter-industry wage differential, $(\beta=1)$, then an improvement in the terms of trade raises the rate of economic growth above that which would result at constant commodity prices. Conversely, a deterioration in the terms of trade will cause the rate of economic growth to be slower than would result at constant commodity prices.

2) If $\beta<1$, (i.e., $\alpha<1$ or $w_{1}>w_{2}$, that is, if the wage differential works against $\mathrm{X}_{1}$, the exportable commodity), then an improvement in the terms of trade raises the rate of economic growth above that which would result at constant commodity prices, and this increase in the growth rate will be even greater than was the case when $\beta=1$. Conversely, a deterioration in the terms of trade will result in a rate of growth slower than that which would prevail under constant commodity prices and this rate will be even slower than that which would occur if $\beta=1$.

3) However, if $\beta>1$, (i.e., $\alpha>1$ or $w_{1}<w_{2}$, that is, if the wage differential works against $x_{2}$, the importable comodity), then an improvement in the terms of trade will result in a rate of economic growth lower than that which would have occurred at constant commodity prices. The necessary condition for this result to occur is again given by formula (5). On the other hand, a deterioration in the terms of trade will result in a rate of economic growth higher than that which would have resulted in the presence of constant commodity prices! In other words, the traditional results that an improvement in the terms of trade must raise a country's growth rate, and a deterioration must lower it, may not hold in the presence of an interindustry wage differential such that $\beta>1$. Thus, the relationship between 
the rate of economic growth and the terms of trade is not unique.

This conclusion is of relevance to the Prebisch view, prevalent in Latin America, that a Latin-American-growth-induced deterioration in the terms of trade has reduced the Latin American rate of growth. Our analysis indicates that this is not a necessarily correct view when there is a wage differential against the importable commodity: as indeed would seem to be the case with Latin America whose exports have typically been primary products and imports have been manufactures.

\section{III}

So far we have tacitly assumed in section II that economic growth at constant terms of trade is positive, that is to say, $\left.\underline{\partial Y}\right|_{p}>0$. However, it has been shown by Bhagwati (1968), and more formally established recently by Batra and Casas (1970) that $\left.\underline{\partial Y}\right|_{\vec{p}}$ may be negative provided factor markets are distorted and growth is ultra-biased against any commodity. ${ }^{3}$ In other words, in the presence of the wage differential, growth may be immiserizing even at unchanged terms of trade. However, it can be seen that formula (5) clearly leads to the conclusion that immiserizing growth can arise in spite of the improvement in the terms of trade. In the absence of the interindustry wage differential, $(\beta=1), \frac{\partial \mathrm{Y}}{\overline{\mathrm{Y}}}$ is positive, so that a deterioration in the terms of trade, (dp $<0)$, becomes a necessary condition for growth to be immiserizing. In the presence of the wage differential $(\beta \lessgtr 1)$, $\left.\frac{\partial \mathrm{Y}}{\mathrm{Y}}\right|_{\overline{\mathrm{P}}}<0$, so that a deterioration in the terms of trade is no longer a necessary condition for immiserization. Moreover, even if the terms of trade improve, (dP $>0$ ), the real income may still decline as a result of growth. 
The theorems established in previous sections can easily be shown as special cases of the generalized theory of immiserizing growth. This theory (Bhagwati; 1968 and 1969) states that if growth takes place in a country characterized by (a distortion and hence by) a sub-optimal policy, then immiserizing growth can ensue; and conversely growth cannot be immiserizing if optimal policies are pursued (before and after growth). Growth can only improve welfare if optimal policies are pursued; however, if suboptimal policies are followed before and after growth, immiserizing growth will ensue if the primary gain from growth, measured as the gain which would accrue if optimal policies were followed, is outweighed by the incremental loss that could arise from the pursuit instead of sub-optimal policies. The theory of immiserizing growth can be used to illuminate and prove other propositions of growth theory where no growth, in an obvious sense, is involved. Thus the classic propositions of Gottfried Haberler (1950), which compare free trade (i.e., laissez-faire) with no trade (i.e., autarky) and demonstrate that the two policies cannot be ranked uniquely if production externalities or factor price rigidities are present, can be readily seen to be examples of the theory of immiserizing growth. This is because, as Baldwin (19.52) has shown, the free trade-situation availability locus lies uniformly outside (except for overlaps) the production-possibility curve which is, of course, the no-trade-situation availability locus. Thus, the nowtrade and free-trade policies are conceptually the same as pre-growth and post-growth situations. Hence, if a distortion is present in the two situations, so that the two situations are sub-optimal, immiserizing growth can follow; that is to say, free trade can be inferior to no trade. 
The Batra-Pattanaik paradox (established in section I) also falls into place in a similar fashion. The exogenous improvement in the terms of trade implies an outward shift of the Baldwin availabilities locus, implying "growth;" and the presence of the distortionary wage-differential implies that this "growth" is occurring in the presence of sub-optimal policies. Hence "immiserizing growth" can occur: that is to say, an exogenous improvement in the terms of trade can worsen welfare.

The propositions established in section III are also to be explained in similar terms. For a small country following a policy of laissez faire in the presence of the distortionary wage-differential, growth may be immiserizing if the output expansion is ultra biased against any commodity. This possibility is depicted in Figure 1 where TT' and GG' are the pre-growth and post-growth transformation curves, PC indicates the pregrowth terms of trade, and the welfare level is given by the community indifference curve $U_{3}$. After growth at constant terms of trade, the production and consumption points are given by $P^{\prime}$ and $C^{\prime}$ and welfare declines to $U_{1}$. Even though the terms of trade improve to $P^{\prime \prime} C^{\prime \prime}$, the welfare level given by $\mathrm{U}_{2}$ is below the pre-growth welfare level of $\mathrm{U}_{3}$. Here again the cause of immiserization is the sub-optimality arising from the distortionary wage-differential which exists before and after growth. 
Footnotes

$*$ We are extremely grateful to the very generous suggestions from Professor Bhagwati on the initial draft of this paper. In its present form, the paper owes much to his comments. Batra's research was undertaken while he was Assistant Professor at Southern Illinois University.

1. This proof has been obtained from Hagen (1958).

2. Where $\bar{P}$ denotes constant terms of trade, and $\bar{G}$ stands for constant growth.

3. It may be noted that the possibility of the negative sign of $\frac{\partial \mathrm{Y}}{\overline{\mathrm{Y}}} \overrightarrow{\mathrm{p}}$ in the presence of the wage-differential does not invalidate the theorems proved in section II. 
Baldwin, R. E., 1952, "The New Welfare Economics and Gains in International Trade," Quarterly Journal of Economics, 66, 91-101.

Batra, R. and P. K. Pattanaik, 1970, "Domestic Distortions and the Gains from Trade," Economic Journal, forthcoming.

Batra, R. and F. R. Casas, 1970, "Economic Growth and International Trade Under Imperfect Factor Markets,"mimeographed.

Bhagwati, J. N., 1968, "Distortions and Immiserizing Growth: A Generalization," Review of Economic Studies, 35, 481-85.

Bhagwati, J. N., 1969, "The Generalized Theory of Distortions and Welfare," Working Paper No. 39, Department of Economics, Massachusetts Institute of Technology.

Bhagwati, J. N. and V. K. Ramaswami, 1963, "Domestic Distortions, Tariffs and the Theory of Optimum Subsidy," Journal of Political Economy, 71, 44-50. Bhagwati, J. N. and T. N. Srinivasan, 1970, "The Theory of Wage Differentials: Production Response and Factor Price Equalization," Working Paper No. 51 , Department of Economics, Massachusetts Institute of Technology. Fishlow, A. and P. A. David, 1961, "Optimal Resource Allocation in an Imperfect Market Setting," Journal of Political Economy, 69, 529-46.

Hagen, E. E., 1958, "An Economic Justification of Protectionism," Quarterly Journal of Economics, 72, 496-514.

Johnson, H. G., 1966, "Factor Market Distortions and the Shape of the Transformation Curve," Econometrica, 34, 686-98.

Kemp, M. C. and H. Herberg, 1969, "Factor Market Distortions, the Shape of the Locus of Competitive Outputs, and the Relation Between Product Prices and Equilibrium Outputs," Discussion Paper, University of Southampton. 
$-11-$

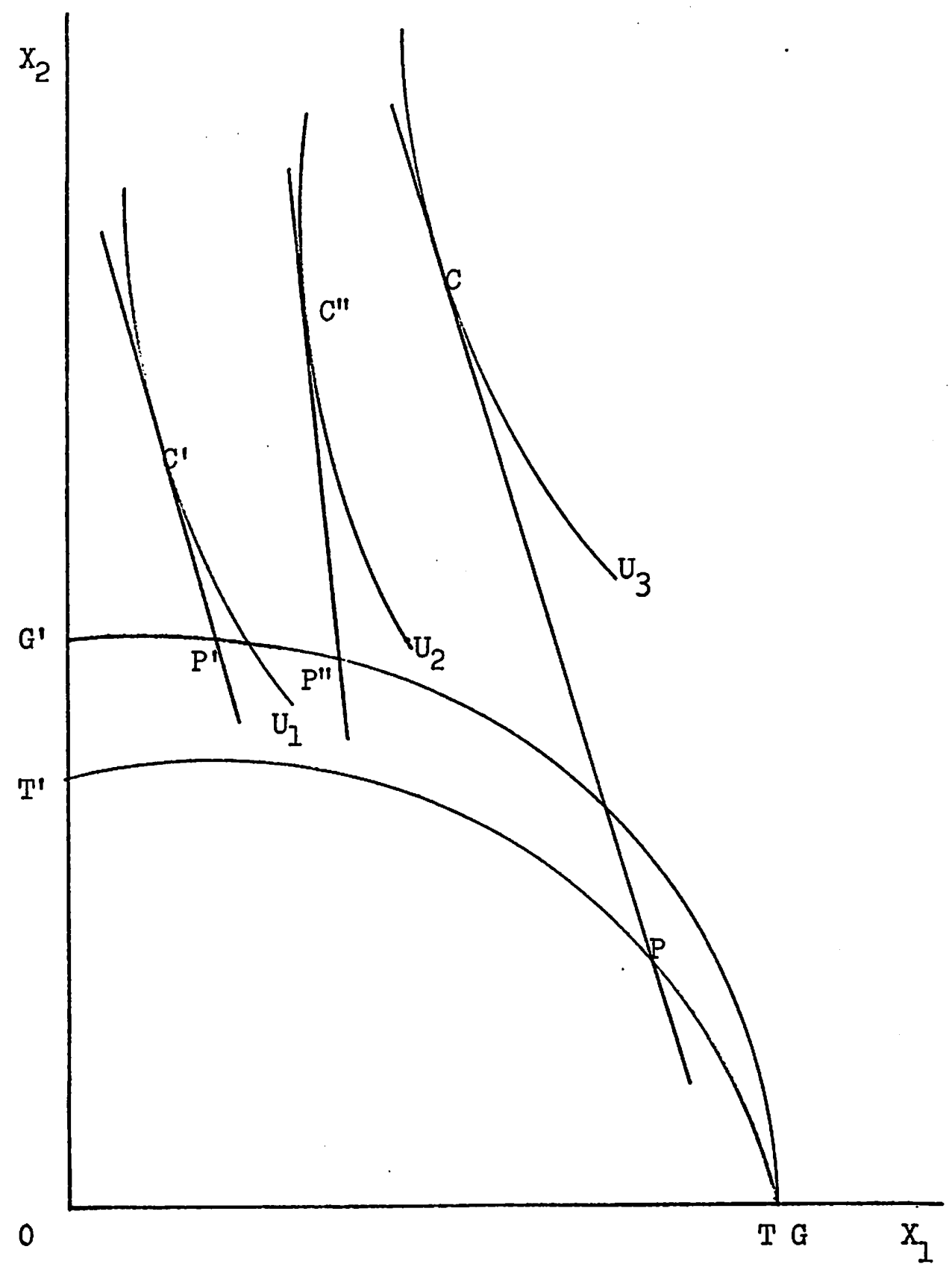

Figure 1 